\title{
Brain Changes Associated with Postural Training in Patients with Cerebellar Degeneration: A Voxel-Based Morphometry Study
}

\author{
Roxana Gabriela Burciu, ${ }^{1}$ Nicole Fritsche, ${ }^{1}$ Oliver Granert, ${ }^{3}$ Lutz Schmitz, ${ }^{1}$ Nina Spönemann, ${ }^{1}$ Jürgen Konczak, ${ }^{4}$ \\ Nina Theysohn, ${ }^{2}$ Marcus Gerwig, ${ }^{1}$ Thilo van Eimeren, ${ }^{3}$ and Dagmar Timmann ${ }^{1}$ \\ ${ }^{1}$ Department of Neurology and ${ }^{2}$ Department of Diagnostic and Interventional Radiology and Neuroradiology, University of Duisburg-Essen, Essen 45147, \\ Germany, ${ }^{3}$ Department of Neurology, University of Kiel, Kiel 24118, Germany, and ${ }^{4}$ Human Sensorimotor Control Laboratory, University of Minnesota, \\ Minneapolis 55455
}

Recent research indicates that physiotherapy can improve motor performance of patients with cerebellar degeneration. Given the known contributions of the cerebellum to motor learning, it remains unclear whether such observable changes in performance are mediated by the cerebellum or cerebral brain areas involved in motor control and learning. The current study addressed this question by assessing the increase in gray matter volume due to sensorimotor training in cerebellar patients using voxel-based morphometry. Nineteen human subjects with pure cerebellar degeneration and matched healthy controls were trained for 2 weeks on a balance task. Postural and clinical assessments along with structural magnetic resonance imaging were performed pretraining and post-training. The main findings were as follows. First, training enhanced balance performance in cerebellar patients. Second, in contrast to controls patients revealed significantly more post-training gray matter volume in the dorsal premotor cortex. Third, training-related increase in gray matter volume was observed within the cerebellum and was more pronounced in controls than in patients. However, statistically cerebellar changes were at the trend level and thus require additional, independent confirmation. We conclude that sensorimotor training of patients with cerebellar neurodegeneration induces gray matter changes primarily within nonaffected neocortical regions of the cerebellar-cortical loop. Residual function of the cerebellum appears to be exploited suggesting either a recovery from degeneration or intact processes of cerebellar plasticity in the remaining healthy tissue.

\section{Introduction}

Sporadic and hereditary cerebellar ataxias are associated with progressive loss of motor coordination severely affecting all aspects of daily life (Klockgether and Paulson, 2011). In recent years, knowledge about genetics of many dominantly and recessive inherited disorders has improved considerably (Durr, 2010; Anheim et al., 2012). So far, with very few exceptions, such as administration of acetazolamide and aminopyridines in episodic ataxias and downbeat nystagmus (Strupp et al., 2011), there is no proven pharmacological treatment that provides significant symptomatic relief or slows disease progression.

Currently, treatment primarily consists of physiotherapeutic interventions (Ilg and Timmann, 2013). Although physical therapy has been recommended for many years, there is a remarkable

Received July 16, 2012; revised Jan. 13, 2013; accepted Jan. 28, 2013.

Author contributions: D.T. designed research; R.G.B., N.F., L.S., N.S., and M.G. performed research; R.G.B., N.F., 0.G., L.S., N.S., J.K., and N.T. analyzed data; R.G.B., O.G., J.K., T.v.E., and D.T. wrote the paper.

This work is supported by Bernd Fink Foundation and Marie Curie Initial Training Network "Cerebellar-Cortical Control: Cells, Circuits, Computation and Clinic."

The authors declare no competing financial interests.

Correspondence should be addressed to Roxana Gabriela Burciu, Department of Neurology, University of Duisburg-Essen, Hufelandstrasse 55, Essen 45147, Germany. E-mail: roxana.burciu@stud.uni-due.de roxana.g.burciu@gmail.com.

DOI:10.1523/JNEUROSCI.3381-12.2013

Copyright $\odot 2013$ the authors $\quad 0270-6474 / 13 / 334594-11 \$ 15.00 / 0$ lack of studies examining its potential benefit for cerebellar patients. Since the cerebellum has long been known as a structure that contributes to motor coordination and motor learning (Ito, 1984; Thach et al., 1992), one may not have been overly optimistic regarding improvement of motor function with training. Yet, only recently, three well controlled group studies have demonstrated significant motor benefit following coordinative training. Ilg et al. $(2009,2010)$ reported that after a 4 week intensive coordinative training cerebellar patients improved motor performance, reduced their ataxic symptoms, and sustained these benefits for up to one year. Similar gains persisting for 6 months following a 1 month rehabilitation program were also shown by Miyai et al. (2012). However, at this point the neuronal underpinnings of the beneficial effect of coordinative training in cerebellar degeneration remain elusive.

Neuroimaging tools-in particular voxel-based morphometry (VBM) -were proven useful for understanding trainingrelated brain changes in healthy participants (Draganski et al., 2004; Driemeyer et al., 2008; Taubert et al., 2010), but as yet, have only rarely been applied in patient populations. In patients with cerebellar degeneration, VBM may show that motor improvement can rely either on the cerebrum or cerebellum. A limited number of studies appear to support both possibilities. First, an animal model of alcohol toxicity-driven cerebellar degeneration showed that training-induced motor improvement is accompa- 
Table 1. Characteristics of cerebellar patients

\begin{tabular}{|c|c|c|c|c|c|c|c|c|c|c|c|c|}
\hline \multirow[b]{2}{*}{ Patient } & \multirow[b]{2}{*}{ Age (years) } & \multirow[b]{2}{*}{ Duration (years) } & \multirow[b]{2}{*}{ Gender } & \multirow[b]{2}{*}{ Disease } & \multicolumn{3}{|c|}{ ICARS [100] } & \multicolumn{3}{|c|}{ SARA [40] } & \multirow[b]{2}{*}{ Cerebellar vol. (\% TICV) } & \multirow[b]{2}{*}{ Cerebellar GM vol. (\%TICV) } \\
\hline & & & & & BT & AT & $\mathrm{A} 3$ & BT & AT & A3 & & \\
\hline P01 & 72 & 5 & M & SCA 6 & 26.5 & 28.5 & 34.5 & 16 & 16 & 18 & 6.5 & 5.6 \\
\hline $\mathrm{P} 02$ & 58 & 5 & M & SAOA & 24.5 & 21 & 14.5 & 15 & 10 & 12 & 7.4 & 6.3 \\
\hline P03 & 58 & 10 & $\mathrm{~F}$ & SCA 6 & 44 & 40 & 47.5 & 26 & 21 & 22 & 7.6 & 6.3 \\
\hline P04 & 71 & 3 & $\mathrm{~F}$ & SCA 6 & 25 & 25 & 27 & 18 & 17 & 18 & 7.4 & 6.1 \\
\hline P05 & 42 & 6 & M & ADCA III & 33 & 28.5 & 30.5 & 13 & 14 & 16 & 6.7 & 5.4 \\
\hline P06 & 63 & 2 & $M$ & SAOA & 26 & 24.5 & 23.5 & 11 & 14 & 15 & 8.8 & 6.9 \\
\hline P07 & 42 & 3 & $M$ & SAOA & 16 & 18 & 16 & 11 & 11 & 10 & 8.5 & 6.8 \\
\hline P08 & 51 & 5 & $M$ & ADCA III & 20.5 & 23.5 & 27 & 11 & 14 & 19 & 6.2 & 5.2 \\
\hline P09 & 51 & 16 & $M$ & SAOA & 48.5 & 40.5 & 45.5 & 26 & 20 & 22 & 6.5 & 5.6 \\
\hline P10 & 46 & 5 & $F$ & ADCA III & 13 & 14 & 14.5 & 10 & 9 & 10 & 5.8 & 4.6 \\
\hline P11 & 70 & 15 & $M$ & SCA 6 & 33 & 28 & 37.8 & 18 & 16 & 20 & 6.3 & 5.3 \\
\hline P12 & 50 & 11 & $F$ & SCA 14 & 23 & 19 & 20.5 & 14 & 14 & 13 & 7.8 & 6.3 \\
\hline P13 & 26 & 3 & $M$ & SAOA & 30.5 & 32 & 29.5 & 19 & 22 & 20 & 6.6 & 5.3 \\
\hline P14 & 62 & 4 & $F$ & SCA 6 & 33 & 32 & 30 & 19 & 17 & 17 & 7.1 & 5.8 \\
\hline P15 & 60 & 5 & $M$ & SAOA & 21 & 26 & 22 & 13 & 13 & 14 & 9.1 & 6.9 \\
\hline P16 & 54 & 3 & $M$ & SCA 6 & 10.5 & 7 & 7.5 & 5 & 4 & 4.5 & 0.8 & 0.7 \\
\hline P17 & 71 & 4 & $M$ & SAOA & 18 & 15.5 & 18 & 10 & 7 & 9 & 7.7 & 6.1 \\
\hline P18 & 50 & 11 & $F$ & SAOA & 27 & 30.5 & 26.5 & 14 & 17 & 16 & 6.7 & 5.4 \\
\hline P19 & 73 & 20 & $M$ & SAOA & 17 & 16.5 & 13.5 & 11 & 9 & 8 & 8.0 & 6.4 \\
\hline
\end{tabular}

Listed are age at examination, disease duration, and gender ( $M=$ male, $F=$ female). In the disease column, SCA 6, 14 indicate spinocerebellar ataxia type 6, type 14; SAOA, sporadic adult-onset ataxia, and ADCA III, autosomal dominant cerebellar ataxia type III (pure cerebellar type). Severity of ataxia was rated on three occasions: BT, before training; AT, after training, and A3, 3 month follow-up; using the International Cooperative Ataxia Rating Scale (ICARS) and the Scale for the Assessment and Rating of Ataxia (SARA). Total scores are given, with maximum scores indicated in brackets. The last two columns document volumes of the cerebellum and cerebellar gray matter (GM) in patients expressed as percentage of the total intracranial volume (\%TICV). For comparison purposes, we provide the mean values (SD) for patients and controls: cerebellar volume patients, 6.9 (1.7); cerebellar volume controls, 9.4 (1.1); cerebellar gray matter volume patients, $5.4(1.4)$; cerebellar gray matter volume controls, 7.7 (0.9).

nied by synaptogenesis of remaining Purkinje cells and an increase in the size of astrocytes (Klintsova et al., 2002). Thus, training may improve function of remaining cerebellar circuitry. Second, there is proof that in Parkinson's disease, corticocerebellar motor loops are increasingly recruited as a form of compensation for the affected basal ganglia circuit (van Eimeren and Siebner, 2006; Palmer et al., 2009). Therefore, it may be reasonable to expect the opposite in cerebellar patients (Wessel et al., 1995). Specifically, motor deficits in degenerative cerebellar patients may be compensated by gray matter increase within structures of the corticobasal ganglia motor loop.

The primary goals of the present study were to provide additional evidence that sensorimotor training enhances motor performance in adults with cerebellar degeneration and identify possible training-related changes in gray matter volume in cerebellar and/or cortical areas by means of VBM.

\section{Materials and Methods}

Participants. A total of 19 patients with cerebellar degeneration (13 males, mean age $56.3 \pm 12$ years, age range $26-73$ years, mean disease duration $7.3 \pm 5$ years) and an equal number of age-matched healthy participants (11 males, mean age $53.5 \pm 12.9$ years, age range $25-71$ years) took part in the study. All patients had disorders known to primarily affect the cerebellar cortex (Timmann et al., 2009): spinocerebellar ataxia (SCA) type 6, SCA 14 (one patient), sporadic adult onset ataxia, and autosomal dominant cerebellar ataxia type III (for more details, see Table 1). Thus, although the underlying cause of these disorders differs, the cerebellar structures involved are the same. As for controls, there was no evidence of any neurological or orthopedic disease based on medical history and neurological examination. The study was approved by the local Ethics Committee and complied with the principles outlined in the Declaration of Helsinki. Informed consent was obtained from all participants before testing.

Study design. The aim of the present study was to assess the effects of a 2 week postural training program on motor performance as well as accompanying gray matter changes in patients with cerebellar degeneration. For this purpose, participants underwent 2 weeks of training. Postural assessment, clinical examination, and structural magnetic resonance imaging (MRI) were performed on three different occasions: be-

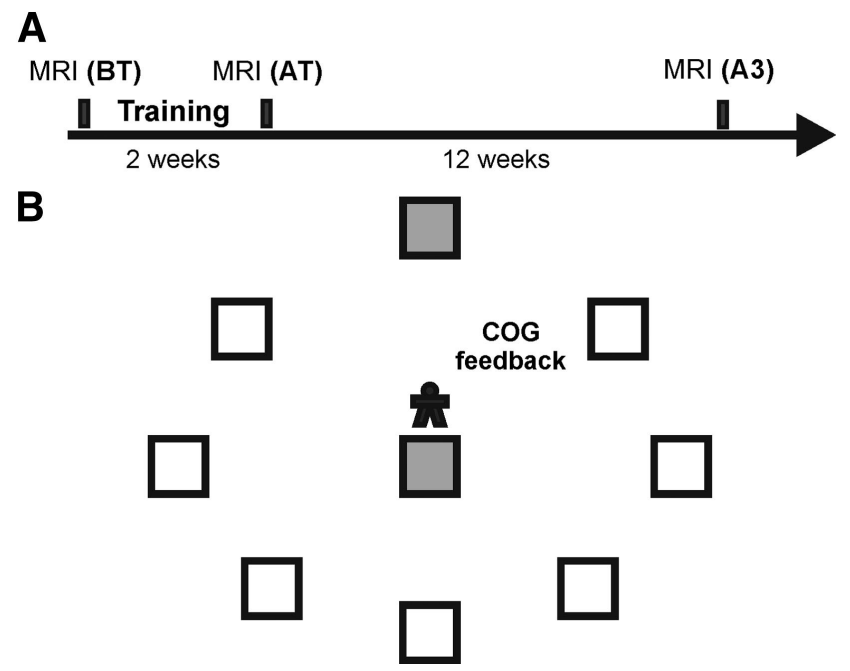

Figure 1. $\boldsymbol{A}$, Schematic representation of the experimental design. $\boldsymbol{B}$, LOS target layout. Participants were asked to displace their $\mathrm{COG}$ as smoothly and as far as possible to reach each cued location (gray color). On-line feedback of their $\mathrm{COG}$ trace was offered via a human-shaped cursor.

fore training (BT), after training (AT), and 3 months later (A3) (Fig. 1A). To exclude unspecific, nontraining-related effects on behavioral measures, half of the participants (chosen at random) received additional postural and clinical assessments 2 weeks before the beginning of the training.

Postural training. The 2 week postural training was conducted by a qualified physical therapist (N.F.). Due to local organizational requirements, it always started on a Tuesday and included two weekends. The program was delivered in the form of a $10 \mathrm{~d}$ assisted training on a NeuroCom SMART EquiTest system along with a $4 \mathrm{~d}$ home training session corresponding to the two weekends.

The testing protocol required participants to stand on a force plate while facing a visual surround. Both could either tilt or remain fixed depending on the testing condition. Throughout the experiment, patients and controls were protected from falling by a safety harness. A 
central starting position and target locations were presented as squares on a computer screen situated in front of them, at the level of their eyes. On command (that is, a change in target color, followed by a beep), they had to displace their center of gravity (COG) to reach for the cued location. The instructions were to move "as quickly and as accurately as possible" and maintain their COG within the target area for $10 \mathrm{~s}$ before moving to a different location. Visual feedback of their COG displacement was provided via a cursor on the screen. Training consisted of $1 \mathrm{~h}$ daily sessions, divided into three 20 min blocks. There were three exercises per block $(3 \times 5 \mathrm{~min})$. At the end of each block, participants' postural control was assessed using the limits of stability (LOS) test (see Postural assessments). The first exercise contained clusters of four targets, located on the screen directly forward, backward, to the right, and to the left of the starting position. Patients and controls were required to displace their COG so they could reach each target within a cluster. Moving to a different cluster was possible only after having passed through all four targets. The second exercise involved a central starting point and 20 target locations that were highlighted in a random manner. Both exercises were performed with a fixed base of support. The last exercise was a repetition of the first one, while standing on a moving platform. The base of support would now move in the anterior-posterior direction according to the participant's sway (sway-referenced). The difficulty level of the exercises could increase depending on whether a "plateau effect" was detected during 3 consecutive days. Overall, changes were made for half of the participants ( 3 patients, 16 controls), mostly during the second week of training. The new adjustment comprised the reference of the platform to the participant's anterior-posterior body sway during the first two exercises and random motion during the third one. In addition to the performance during the previously mentioned exercises, we also monitored the number of falls. A fall was scored whenever the participant would come to rest against the visual surround or make side steps.

Participants continued their training over the two weekends by performing similar exercises at home. They were provided with an instruction book, eight stickers to tape in a circle on a mirror and one on their sternum (acting like targets and starting position), and a foam pad to simulate the moving platform. Home training lasted half an hour a day and had to be done in a single session.

Clinical outcome measures. Experienced neurologists (D.T./M.G.) rated ataxia using the International Cooperative Ataxia Rating Scale (ICARS; Trouillas et al., 1997) and the Scale for the Assessment and Rating of Ataxia (SARA; Schmitz-Hübsch et al., 2006).

Additionally, the physiotherapist (N.F.) evaluated balance capacities using a battery of motor tests. Participants' ability to maintain balance while performing a series of 14 tasks required in everyday living was rated using the Berg Balance Scale (BBS; Berg et al., 1992). A low score on this scale is associated with a high risk of falling. Mobility was assessed using the Timed Up and Go Test ( Podsiadlo and Richardson, 1991), while the speed of gait was evaluated with the Timed Walking Test: $8 \mathrm{~m}$ walk (a subunit of the Spinocerebellar Ataxia Functional Index; Schmitz-Hübsch et al., 2008). Finally, the Falls Efficacy Scale International ( Yardley et al., 2005), a specific screening instrument measuring self-reported fear of falling, was used to determine how confidently participants felt when undertaking certain activities.

Postural assessments. A comprehensive assessment was performed using two testing protocols available on the NeuroCom SMART EquiTest system that cover both static and dynamic components of postural stability.

First, a test that addresses the concept of theoretical LOS was used. The LOS is pictured as a cone with its apex projecting from the center of the base of support. The area within the cone corresponds to the maximum range in which the COG can be safely displaced without changing the base of support (NeuroCom International, 2004). The LOS are represented by an ellipse of eight predefined targets arrayed around a central position on a computer screen situated at the level of the eyes (Fig. 1B). Once a peripheral target was highlighted, the participant had to use the ankle strategy to move a cursor on the screen reflecting their COG position to the cued location, and hold it in position for $10 \mathrm{~s}$ until the central position was again indicated. The LOS targets were specified in a clock- wise manner. For each of the eight directions, the system calculated online the following parameters: reaction time (RT; time from the moment a participant was acoustically cued to move and the actual initiation of movement), movement velocity (MVL; average speed of COG displacement measured in degrees per second), endpoint excursion (EPE; distance left until reaching the target after the first attempt of moving toward it had been made), maximum excursion (MXE; distance left until reaching the target once the last movement had been made), and directional control (DCL; comparison of the amount of movement in the cued direction and the amount of extraneous movement). The last three parameters were expressed as percentage of the maximum LOS distance.

Second, participants were tested on the Sensory Organization Test (SOT), a task evaluating one's ability to use visual, vestibular, and somatosensory information for balance control (NeuroCom International, 2004). Similar to the LOS testing procedure, participants had to stand on the computer-controlled platform, facing the visual surround, with their feet centered on the force plate and arms alongside the body. The test consisted of six conditions (three trials each). With the platform stable the participant's eyes were either open (condition 1) or closed (condition 2 ), or the visual surround was sway-referenced (condition 3). With the platform being sway-referenced the participant's eyes were either open (condition 4) or closed (condition 5) or both the visual surround and the platform were sway-referenced (condition 6). Throughout the six conditions, participants were required to remain as stable as possible. Collected data were entered into custom-built software based on MATLAB R2007b (MathWorks) to compute several measures of postural sway.

Statistical analysis. Paired-samples $t$ tests (separate for patients and controls) were performed to compare performance 2 weeks and directly before training in the subgroup with the 2 week waiting period, to exclude unspecific improvements unrelated to training ( $p$ values $>0.05$ ). Next, we used an ANOVA with repeated measures on assessment, on all postural parameters, to examine differences between testing sessions as well as groups. Where the ANOVA's sphericity assumption was not met, degrees of freedom were corrected using the Greenhouse-Geisser estimates of sphericity. Significant effects were further examined using a priori pairwise comparisons. By applying a Bonferroni correction to the planned contrasts, the significance level was reduced to $p<0.017$ corresponding to a division of the standard $\alpha$-level to the number of comparisons ( $\mathrm{BT}$ vs $\mathrm{AT}, \mathrm{AT}$ vs $\mathrm{A} 3, \mathrm{BT}$ vs $\mathrm{A} 3$ ). On all clinical scores, nonparametric statistics were applied (Friedman's test followed by Wilcoxon signed-rank test to determine significance between assessments and Mann-Whitney $U$ test to assess group differences). Furthermore, a Pearson product-moment correlation coefficient was computed for each LOS parameter evaluated before training in patients to assess its relation to the degree of ataxia, as indexed by ICARS and SARA scores.

MRI data acquisition. All participants received whole-brain T1weighted structural MRI scans before training, after training, and at 3 month follow-up (Fig. 1A). MRI was performed on a 1.5 T MRI system (Magnetom Espree; Siemens Medical Solutions) with a 12-channel headcoil. Magnetization prepared rapid acquisition gradient echo (MPRAGE) images were acquired using a 3D gradient echo technique (TR $2400 \mathrm{~ms}$, TE $3.63 \mathrm{~ms}$, flip angle $8^{\circ}$, FOV $280 \mathrm{~mm}$, acquisition matrix $256 \times 256$, voxel size $1.0 \times 1.0 \times$ $1.0 \mathrm{~mm}, 1$-mm-thick slices). Moreover, the MRI protocol included a onetime acquisition of T2-weighted (TR $5270 \mathrm{~ms}$, TE $107 \mathrm{~ms}$, FOV $250 \mathrm{~mm}$, voxel size $1.0 \times 0.5 \times 3.0,3$-mm-thick slices), susceptibility weighted imaging (TR $45 \mathrm{~ms}$, TE $40 \mathrm{~ms}$, FOV $280 \mathrm{~mm}$, voxel size $1.0 \times 0.9 \times 1.6,1.6-\mathrm{mm}-$ thick slices), and fluid-attenuated inversion recovery (TR $6000 \mathrm{~ms}$, TE 357 $\mathrm{ms}$, FOV $256 \mathrm{~mm}$, voxel size $1.0 \times 1.0 \times 1.0,1$-mm-thick slices) sequences, to exclude extracerebellar brain pathology (as assessed by a neuroradiologist, N.T.).

VBM protocol and data analysis. Two separate VBM analyses were conducted with the aim of detecting changes in gray matter volume associated with the 2 week postural training in cerebellar patients and healthy controls. Conventional whole-brain VBM analysis along with a cerebellum-optimized approach was used with the purpose of exploring changes within the cerebrum and cerebellum, respectively. The choice of a whole-brain approach over a region-of-interest (ROI) analysis was motivated by the lack of studies exploring which brain areas a cerebellar patient might use to compensate for the underlying disease. Specifically, 
A

Endpoint Excursion
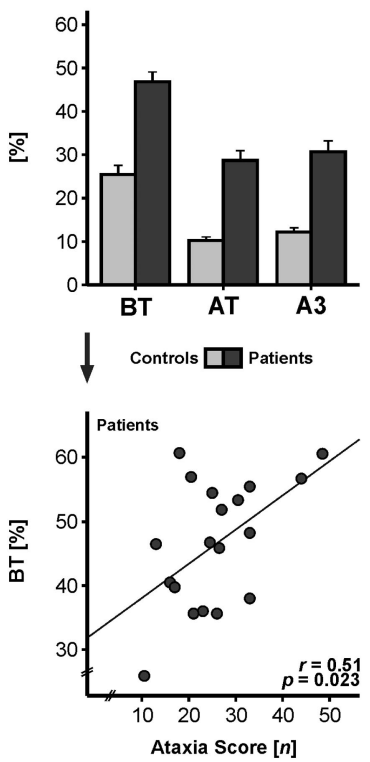

B
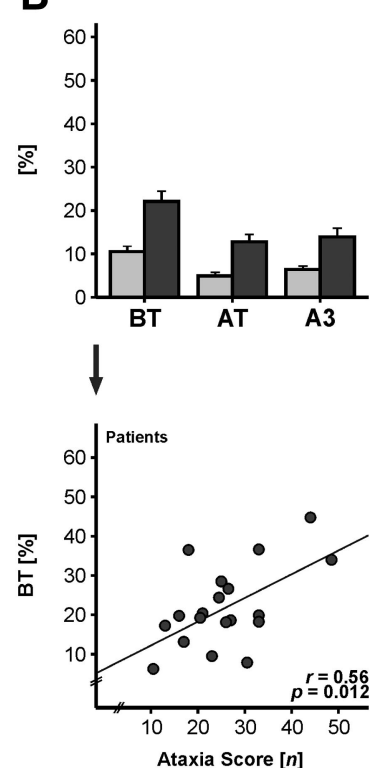

C
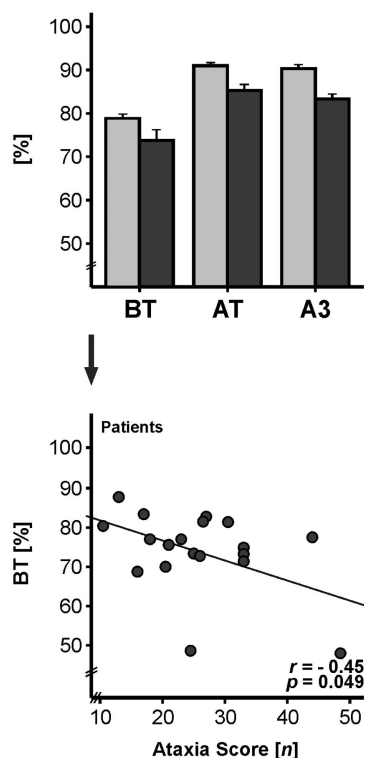

Figure 2. Performance of cerebellar patients and healthy controls on three LOS parameters: EPE $(\boldsymbol{A}), \operatorname{MXE}(\boldsymbol{B})$, and DLC $(\boldsymbol{C})$; expressed as mean scores. Error bars indicate SE. The three groups of bars indicate the main examinations: BT, AT, and A3. Below, scatter plots show a positive correlation of ICARS score with the EPE and MXE, and an inverse correlation with DCL.
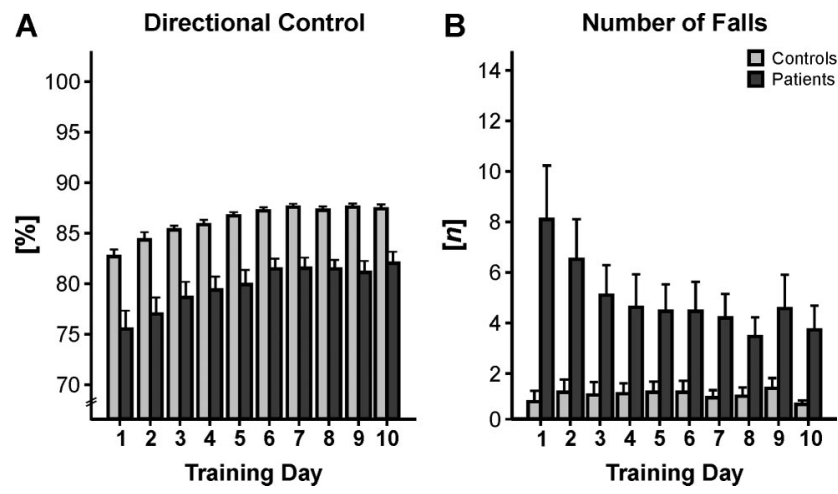

Figure 3. Plots of the mean $D C L$ score $(\boldsymbol{A})$ and number of falls $(\boldsymbol{B})$ of cerebellar patients and healthy controls during the 10 day assisted training. Error bars indicate SE.

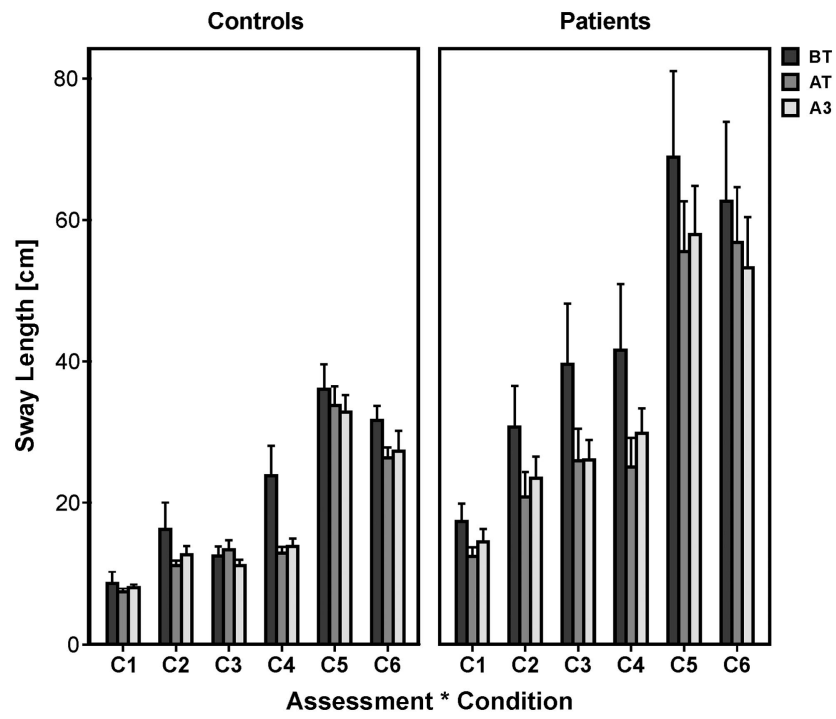

Figure 4. Mean sway length is shown across time, for each of the six SOT conditions. Error bars indicate SE. the brain areas recruited throughout training by these patients may be different from those of healthy individuals. For both analyses, significance was assessed using a corrected height threshold of $p<0.05$ (familywise error (FWE) correction for multiple comparisons). Regions surpassing an uncorrected $p$ value of 0.001 were reported as trends. Predetermined cluster sizes were used as partial correction (Bennett et al., 2009). Statistical inferences were performed on the cluster sizes using random field theory (Friston et al., 1994; Worsley et al., 1996). A different color code shows corrected (green) and uncorrected (red) height threshold data in the respective figures throughout this manuscript.

Standard whole-brain VBM. All T1-weighted MRI scans were preprocessed using VBM8 toolbox (http://dbm.neuro.uni-jena.de/vbm. html) incorporated in the SPM8 software package (Welcome Department of Cognitive Neurology, London, UK). The default longitudinal preprocessing approach implemented in the toolbox was used. Briefly, the after training and 3 month follow-up scans were registered to the baseline (before training) scan for each participant separately. A mean of the realigned images was generated and used as a reference in a subsequent realignment. The resulting realigned images were bias corrected for field inhomogeneities with respect to the reference mean image. The latter was tissue classified into gray matter, white matter, and CSF, and registered using linear (12 parameter affine) and nonlinear transformations (warping to match a standard template; i. e. DARTEL) within a unified model (Ashburner and Friston, 2005). The spatial normalization parameters estimated during this step were applied to the segmentations of the three gray matter maps (BT, AT, A3) to align the coordinate frames of the individual scans. To compensate for individual local volume deformations, resulting gray matter density maps were modulated by the Jacobian determinants as derived from the spatial normalization's deformation parameters. A modulation for nonlinear components only was used. Finally, the modulated normalized gray matter segments were realigned one more time and smoothed with a Gaussian kernel of $8 \mathrm{~mm}$ full width at half-maximum (FWHM).

The processed images (three per participant) were analyzed within the framework of the general linear model implemented in SPM8, by setting up a flexible factorial design. Three factors were specified: subject, group (patients vs controls), and time point (BT, AT, A3). Main effects were investigated using paired-samples $t$ tests. The interaction effect of time and group was calculated. Other usual subject-specific covariates, such as age and total intracranial volume (TICV) were not entered into the design, since the subject factor already accounts for these variances. First, we tested for brain regions showing an increase in gray matter volume from before training to after training in patients and controls, independently. In a second analysis, we looked at brain regions where one group had more gray matter volume increase than the other group (time point $\times$ group interaction). Next, a comparison of baseline gray matter volume between patients and controls was performed via a two-sample $t$ test while controlling for age and TICV. Finally, multiple regression analyses using baseline gray matter volumes and clinical ataxia scores were run in cerebellar patients. Age and TICV were included in the design matrix as covariates of no interest. For result localization, the AAL atlas (Tzourio-Mazoyer et al., 2002) was used.

Cerebellum-optimized VBM. The Spatially Unbiased Infratentorial (SUIT) toolbox was used for an optimized spatial normalization of the cerebellum (http://www.icn.ucl.ac.uk/motorcontrol/imaging/suit.htm; Diedrichsen, 2006). The initial realigned and bias-corrected longitudinal data from the standard whole-brain VBM analysis were used in a processing step that isolated the cerebellum and brainstem from the MRI scans, and generated segmentation maps. Next, the isolated maps were hand corrected 
Table 2. Evaluation of clinical scores

\begin{tabular}{|c|c|c|c|c|c|c|c|c|}
\hline \multirow[b]{2}{*}{ Clinical score } & \multicolumn{4}{|c|}{ Mean ( \pm SD) patients } & \multicolumn{4}{|c|}{ Mean ( \pm SD) controls } \\
\hline & $2 \mathrm{w}<\mathrm{BT}$ & BT & AT & A3 & $2 \mathrm{w}<\mathrm{BT}$ & BT & AT & A3 \\
\hline \multirow[t]{2}{*}{ ICARS [max. 100] } & & $25.7(9.7)$ & $24.7(8.6)$ & $25.5(10.7)$ & & $0.6(0.8)$ & $0.3(0.6)$ & $0.2(0.4)$ \\
\hline & {$[26.1(9.9)]$} & {$[29.2(9.5)]$} & {$[27.5(7.5)]$} & {$[27.7(9.5)]$} & {$[0.8(0.8)]$} & {$[0.3(0.6)]$} & {$[0.3(0.4)]$} & {$[0.2(0.4)]$} \\
\hline \multirow{2}{*}{ SARA $[\max .40]$} & & $14.7(5.3)$ & $13.9(4.7)$ & $14.9(4.9)$ & & $0.5(1.0)$ & $0.4(0.7)$ & $0.1(0.3)$ \\
\hline & {$[14.6(5.1)]$} & {$[17.4(4.7)]$} & {$[16.2(4.0)]$} & {$[17.2(3.6)]$} & {$[0.3(0.5)]$} & {$[0.5(1.3)]$} & {$[0.3(0.7)]$} & {$[0.2(0.4)]$} \\
\hline \multirow[t]{2}{*}{$\mathrm{BBS}[\max .56]$} & & $41(8.5)$ & $42.8(8.1)$ & $42.4(9.1)$ & & $55.2(1.1)$ & $55.2(1.5)$ & $55.2(1.3)$ \\
\hline & {$[40.6(9.8)]$} & [39.7 (10.1)] & {$[41.2(11.1)]$} & {$[41.5(10.4)]$} & {$[55.3(1.1)]$} & {$[55.4(1.1)]$} & {$[55.4(1.0)]$} & {$[55.6(0.7)]$} \\
\hline \multirow[t]{2}{*}{ TUG [seconds $]$} & & $13(7.5)$ & $12.3(6.2)$ & $12.5(6.2)$ & & $6.7(1.0)$ & $6.7(0.8)$ & $6.7(1.0)$ \\
\hline & {$[12.9(7.3)]$} & {$[12.5(5.4)]$} & {$[11.8(5.1)]$} & {$[11.9(4.2)]$} & {$[6.9(1.0)]$} & {$[6.6(0.9)]$} & {$[6.8(0.7)]$} & {$[6.9(1.1)]$} \\
\hline \multirow[t]{2}{*}{ 8MWT [seconds] } & & $8.0(4.4)$ & $7.7(3.8)$ & $8.3(4.9)$ & & $4.7(0.7)$ & $4.9(0.7)$ & $4.9(0.7)$ \\
\hline & {$[8.1(4.4)]$} & {$[7.6(2.7)]$} & {$[7.2(2.3)]$} & {$[7.5(2.3)]$} & {$[4.7(0.8)]$} & {$[4.9(0.6)]$} & {$[5.0(0.6)]$} & {$[4.9(0.7)]$} \\
\hline \multirow[t]{2}{*}{ FES-I [max. 64] } & & $51.1(7.6)$ & $50.9(9.5)$ & $52.3(8.5)$ & & $16.5(0.7)$ & $16.6(0.7)$ & $16.4(0.7)$ \\
\hline & {$[51.8(7.8)]$} & {$[51.4(8.7)]$} & {$[52.7(9.0)]$} & {$[51.7(9.5)]$} & {$[16.5(0.8)]$} & {$[16.4(0.5)]$} & {$[16.4(0.5)]$} & {$[16.2(0.4)]$} \\
\hline
\end{tabular}

Listed are the mean and SD for each clinical outcome measure. ICARS, International Cooperative Ataxia Rating Scale; SARA, Scale for the Assessment and Rating of Ataxia; BBS, Berg Balance Scale; TUG, Timed Up and Go Test; 8MWT, Timed Walking Test: $8 \mathrm{~m}$ walk; FES-I, Falls Efficacy Scale International; $2 \mathrm{w}<\mathrm{BT}$, the performance of those participants who received an additional evaluation 2 weeks prior to the beginning of training. Their performance is given in square brackets throughout the table.

Training-related GM volume increase - PATIENTS
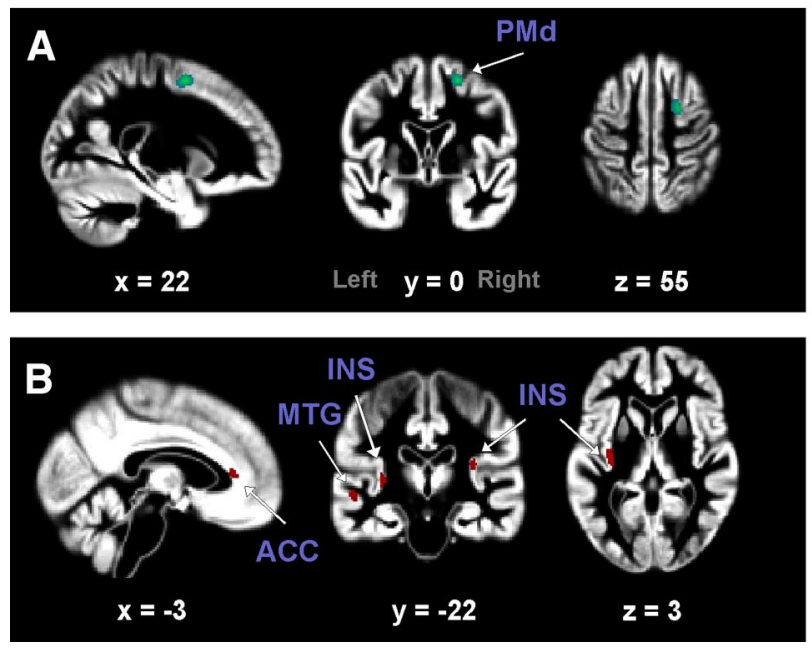

Training-related GM volume increase - CONTROLS
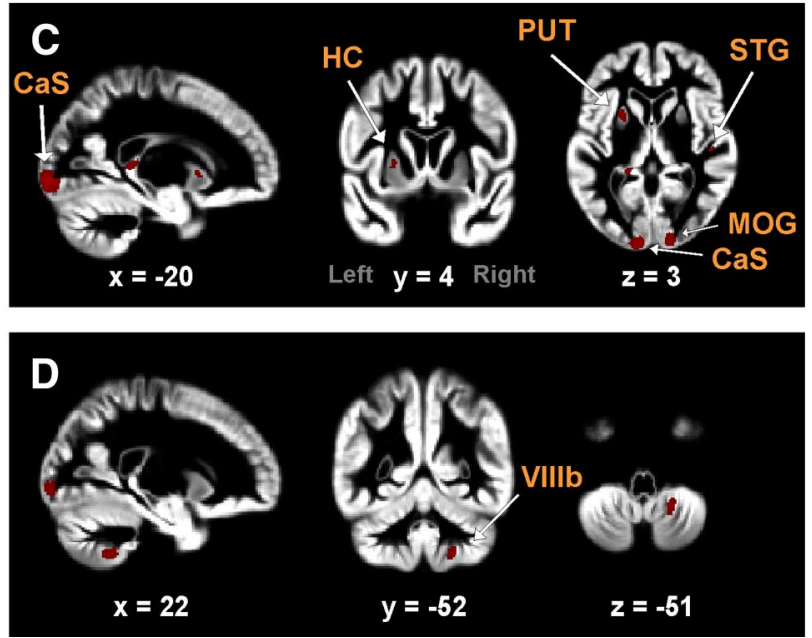
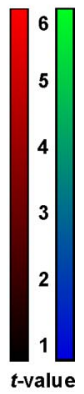

Figure 5. Standard whole-brain VBM analysis results showing increase in gray matter volume from before training to after training in cerebellar patients (left) and healthy controls (right). Training-related gray matter volume increase in patients was detected in the right PMd $(\boldsymbol{A})$ at $p<0.05$ (FWE corrected; shown in green). $\boldsymbol{B}$, At a trend level ( $p<0.001$, uncorrected; predetermined cluster size of 48.29 as partial correction; shown in red), gray matter volume increase was seen in the left middle temporal gyrus, insula bilaterally, and left anterior cingulate cortex. $\boldsymbol{C}$, Conversely, increase in gray matter volume in controls was seen in the calcarine sulcus bilaterally, right superior temporal gyrus, right middle occipital gyrus, left putamen, left hippocampus, and right lobule VIIIb of the cerebellum $(\boldsymbol{D})(p<0.001$, uncorrected; predetermined cluster size of 48.29 as partial correction; shown in red). Gray matter changes are overlaid on a mean image of the modulated normalized gray matter segments. Color scales indicate $t$ values, whereas $x, y, z$ stand for the MNI coordinates in millimeters. GM, gray matter; PMd, dorsal premotor cortex; MTG, middle temporal gyrus; INS, insula; ACC, anterior cingulate cortex; CaS, calcarine sulcus; STG, superior temporal gyrus; MOG, middle occipital gyrus; PUT, putamen; HC, hippocampus; VIIIb, cerebellar lobule VIIIb.

in MRIcron (http://www.cabiatl.com/mricro/mricron/index.html), to avoid contamination problems from the adjacent visual cortex. A spatial normalization of the before training cropped cerebellum to the SUIT template was performed. The resulting normalization parameters were used to reslice the three gray matter segments of each participant into SUIT atlas space. Moreover, a modulation of the gray matter segments was incorporated to compensate for volume changes during spatial normalization by multiplying the intensity value in each voxel with the Jacobian determinants. To preserve precision in the definition of cerebellar structures, a $4 \mathrm{~mm}$ default FWHM Gaussian kernel was used for smoothing. As for the statistical analysis, we specified the same contrasts as in the standard whole-brain VBM analysis. Anatomical localization of the cerebellar lobules was determined with the probabilistic MRI atlas of the human cerebellum (Diedrichsen et al., 2009).

\section{Results}

\section{Postural data}

LOS: pre-, post, and 3 month follow-up assessments

Figure 2 (upper row) illustrates training-related improvement on three of the LOS outcome measures in cerebellar patients and con- trols. A 3 (time of assessment) $\times 2$ (group) repeated-measures ANOVA yielded a significant effect of time of assessment on RT $\left(F_{(1.3,50.1)}=19.82, p<0.001\right), \operatorname{MVL}\left(F_{(1.5,57)}=17.45, p<0.001\right)$, $\operatorname{EPE}\left(F_{(2,72)}=79.98, p<0.001\right), \operatorname{MXE}\left(F_{(2,72)}=19.35, p<0.001\right)$, and DCL $\left(F_{(1.2,45.7)}=64.22, p<0.001\right)$. Planned pairwise comparisons revealed a post-training improvement in performance on all five LOS parameters ( $p$ values $<0.017$; Bonferroni corrected), with no significant decline at 3 month follow-up ( $p$ values $>0.017$ ). As expected, significant group effects (RT: $F_{(1,36)}=7.18, p=0.011$; MVL: $F_{(1,36)}=18.12, p<0.001$; EPE: $F_{(1,36)}=81.23, p<0.001$; MXE: $F_{(1,36)}=29.75, p<0.001$; DCL: $\left.F_{(1,36)}=11.32, p=0.002\right)$, with a better performance of controls compared with that of degenerative patients, were detected. There was, however, no time of assessment $\times$ group interaction, indicating that the pattern of training-related improvement did not differ between groups ( $p$ values $>0.05$ ).

Bivariate Pearson's correlation analyses in patients showed that performance before training on three LOS parameters was 
Table 3. Summary of brain regions detected with standard whole-brain VBM analysis

\begin{tabular}{|c|c|c|c|c|c|c|c|c|}
\hline \multirow[b]{2}{*}{ Brain region } & \multirow[b]{2}{*}{$B A$} & \multirow[b]{2}{*}{ Side } & \multicolumn{3}{|c|}{ MNI peak coordinate $(\mathrm{mm})$} & \multirow[b]{2}{*}{$k_{E}$} & \multirow[b]{2}{*}{$t$ value } & \multirow[b]{2}{*}{ Z-score } \\
\hline & & & $x$ & $y$ & $z$ & & & \\
\hline \multirow{2}{*}{\multicolumn{9}{|c|}{$\begin{array}{l}\text { Training-related gray matter volume } \\
\text { increase }\end{array}$}} \\
\hline & & & & & & & & \\
\hline \multicolumn{9}{|l|}{ Patients } \\
\hline Dorsal premotor cortex & 6 & $\mathrm{R}$ & 22 & 0 & 55 & 160 & 5.23 & 4.80 \\
\hline$\overline{\text { Middle temporal gyrus }}$ & 22 & L & -48 & -19 & -6 & 128 & 4.30 & 4.04 \\
\hline Insula & 13 & $\mathrm{R}$ & 33 & -27 & 19 & 87 & 4.21 & 3.97 \\
\hline Insula & 13 & L & -34 & -15 & 3 & 145 & 3.90 & 3.70 \\
\hline Anterior cingulate cortex & 24 & L & -3 & 33 & 9 & 50 & 3.68 & 3.51 \\
\hline \multicolumn{9}{|l|}{ Controls } \\
\hline Calcarine sulcus & 17 & $\mathrm{~L}$ & -15 & -99 & -6 & 1140 & 4.59 & 4.28 \\
\hline Superior temporal gyrus & 22 & $\mathrm{R}$ & 48 & -24 & 4 & 109 & 4.54 & 4.25 \\
\hline Middle occipital gyrus & 19 & $\mathrm{R}$ & 30 & -88 & 13 & 315 & 4.49 & 4.20 \\
\hline Putamen & - & $\mathrm{L}$ & -24 & 9 & 1 & 117 & 3.91 & 3.71 \\
\hline Calcarine sulcus & 17 & $\mathrm{R}$ & 15 & -97 & -2 & 504 & 3.91 & 3.71 \\
\hline Hippocampus & - & $\mathrm{L}$ & -18 & -37 & 6 & 69 & 3.82 & 3.63 \\
\hline Cerebellum, VIIIb & - & $\mathrm{R}$ & 22 & -52 & -51 & 130 & 3.56 & 3.41 \\
\hline \multicolumn{9}{|c|}{ Between-group gray matter differences } \\
\hline \multicolumn{9}{|c|}{ Patients $>$ Controls } \\
\hline Insula & 13 & $\mathrm{~L}$ & -44 & -33 & 21 & 49 & 4.19 & 3.95 \\
\hline Dorsal premotor cortex & 6 & $\mathrm{R}$ & 22 & 0 & 55 & 50 & 4.06 & 3.84 \\
\hline \multicolumn{9}{|l|}{ Controls $>$ Patients } \\
\hline- & - & - & - & - & - & - & - & - \\
\hline
\end{tabular}

Morphological changes are tabulated in terms of brain region, corresponding Brodmann area (BA) and side (L, left; R, right). Brain regions surviving a height threshold of $p<0.05$ (FWE corrected; underlined) and $p<0.001$ (uncorrected; predetermined cluster size of 48.29 as partial correction) are shown. Stereotactic coordinates (MNI, Montreal Neurological Institute), as well as cluster extent $\left(k_{E}\right)$ and $t / Z$-scores are given for the voxel showing the strongest effect size within a cluster.

associated with the degree of ataxia (Fig. 2, lower row). A first parameter that positively correlated with ICARS $(r=0.51, p=$ $0.023)$ and SARA $(r=0.54, p=0.015)$ was the EPE. A similar correlation was demonstrated for the MXE (ICARS: $r=0.56, p=$ 0.012 ; SARA: $r=0.58, p=0.008)$. DLC before training negatively correlated with ICARS score $(r=-0.45, p=0.049)$. Thus, the distance left toward the target increased and accuracy of movement decreased with the severity of ataxia.

\section{LOS during postural training}

The 2 week postural training resulted in significant improvement of motor performance, visible across the 10 training days. An example of an LOS parameter that changed throughout training is shown in Figure $3 A$. Notably, DCL improved in both groups during the course of training. However, as expected, controls generally performed better than patients. A repeated-measures ANOVA confirmed an improvement across the 10 training days not only for DLC $\left(F_{(2.9,105.4)}=36.62, p<0.001\right)$, but also for $\operatorname{MVL}\left(F_{(4.1,148.6)}=12.36, p<0.001\right), \operatorname{EPE}\left(F_{(5.5,200.2)}=43.89\right.$, $p<0.001)$, and $\operatorname{MXE}\left(F_{(5,183.1)}=7.87, p<0.001\right)$. Training day had no effect on RT ( $p>0.05)$. Between-group differences in RT $\left(F_{(1,36)}=7.71, p=0.004\right), \operatorname{MVL}\left(F_{(1,36)}=12.52, p=0.001\right), \mathrm{EPE}$ $\left(F_{(1,36)}=41.77, p<0.001\right), \operatorname{MXE}\left(F_{(1,36)}=13.05, p=0.001\right)$, and $\operatorname{DLC}\left(F_{(1,36)}=24.99, p<0.001\right)$ revealed an overall better performance of controls compared with patients. A training day $\times$ group interaction was found for $\operatorname{MVL}\left(F_{4.1,148.6)}=2.63\right.$, $p=0.035)$ and $\operatorname{MXE}\left(F_{(5,183.1)}=5.78, p<0.001\right)$ but not for RT, $\mathrm{EPE}$, and DLC ( $p$ values $>0.05)$.

\section{Falls during postural training}

As depicted in Figure $3 B$, the number of falls in cerebellar patients was larger than in controls. Training resulted in a decrease in falls in patients only. A repeated-measures ANOVA revealed a significant group effect $\left(F_{(1,36)}=14.09, p<0.001\right)$, with patients falling more often than controls. No significant training day effect was detected $(p>0.05)$. A trend toward a training day $\times$ group interaction was observed $\left(F_{(3.4,124.6)}=2.19, p=0.082\right)$.

\section{SOT}

Figure 4 shows the mean sway length during the six SOT conditions BT, AT, and A3. A group difference is evident, with patients performing overall worse than controls but with both groups getting better across time. Sway length increased with the difficulty of the condition regardless of the group and so did the number of falls (data not shown). A repeated-measures ANOVA with time of assessment (BT, AT, A3) and group as within/between factors, revealed a shortening in time of sway length (mean over the six conditions) $\left(F_{(1.2,45.5)}=8.15, p=0.004\right)$. Planned pairwise comparisons indicated that sway length was reduced after training compared with before training $(p<0.001)$ and that the improvement was maintained over the following 3 month period ( $p=0.054)$. Between-group differences were also significant $\left(F_{(1,36)}=14.41, p=0.001\right)$. No time of assessment $\times$ group interaction was found $(p=0.197)$.

\section{Clinical outcome measures}

Controls scored better than patients on all clinical measures including the BBS. Respective Mann-Whitney $U$ tests showed significant group effects ( $p$ values $<0.001$ ). Using Friedman's test, possible changes in balance ability between assessments as measured by the BBS yielded a significant effect for time of assessment $\left(\chi_{(2)}^{2}=7.83, p=0.020\right)$. Post hoc analysis with Wilcoxon signed-rank test revealed a significant post-training reduction of the risk of falling in cerebellar patients $(Z=$ $-2.31, p=0.021)$, but no significant change 3 months later $(p=0.755)$. Based on the BBS, controls showed no significant improvements over time and BBS changes within the cerebellar group were small. In addition, repeated testing (familiarity) may have influenced their scores. There was no time of 

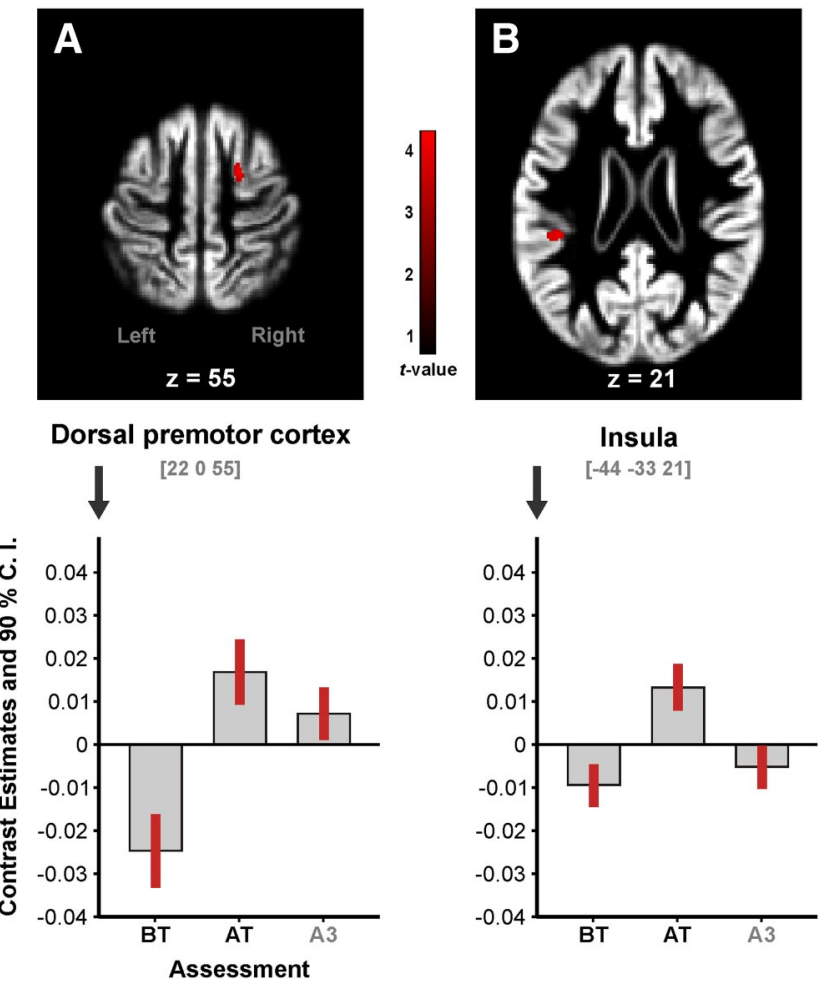

Figure 6. Group analysis showing brain regions where patients had more gray matter volume increase from before training to after training than healthy controls: PMd $(\boldsymbol{A})$ and insula (B). Bottom plot displays changes over time based on $\beta$ parameter estimates (with $90 \%$ confidence interval) of the peak voxel within the respective clusters $(\boldsymbol{B})$. Note that these plots are meant for illustration purposes only. The statistical parametric maps are overlaid on the mean image of the modulated normalized gray matter segments and thresholded at $p<0.001$ (uncorrected; predetermined cluster size of 48.29 as partial correction). Color scale indicates $t$ values, whereas the $z$ coordinates represent the MNI coordinates. GM, gray matter.

assessment effect for the other clinical scores ( $p$ values $>$ 0.05). Results on clinical scores are listed in Table 2.

\section{VBM data}

Standard whole-brain VBM

Training-related gray matter volume increase. VBM analysis revealed a significant post-training gray matter volume increase in the cerebellar group in the right dorsal premotor cortex $(x=22$, $y=0, z=55 ; p<0.05$, FWE corrected; Fig. 5, green; Table 3). At $p<0.001$ (uncorrected; predetermined cluster size of 48.29 as partial correction), further gray matter volume increase was found in the left middle temporal gyrus (left: $x=-48, y=$ $-19, z=-6$; $p<0.001$ ), insula bilaterally (left: $x=-34, y=$ $-15, z=3$, right: $x=33, y=-27, z=19)$, and left anterior cingulate cortex $(x=-3, y=33, z=9)$ (Fig. 5, left, indicated in red; Table 3$)$.

In contrast, healthy controls had less pronounced gray matter changes following training. No training-related gray matter volume increases were observed at a height threshold of $p<0.05$ corrected for multiple comparisons. The corresponding analysis using an uncorrected height threshold ( $p<0.001$; predetermined cluster size of 48.29) revealed increases in gray matter volume in the calcarine sulcus bilaterally (left: $x=-15, y=-99$, $z=-6$, right: $x=15, y=-97, z=-2)$, right superior temporal gyrus $(x=48, y=-24, z=4)$, right middle occipital gyrus $(x=$ $30, y=-88, z=13)$, left putamen $(x=-24, y=9, z=1)$, and left hippocampus $(x=-18, y=-37, z=6)$. An additional cluster was seen in the right lobule VIIIb of the cerebellum $(x=22$, $y=-52, z=-51$ ). For more details, see Figure 5, right and Table 3 .

Between-group gray matter differences. Next, group differences in the context of training-related gray matter changes were assessed. At $p<0.001$ (uncorrected; predetermined cluster size of 48.29) patients showed more post-training gray matter volume increase compared with healthy controls in right dorsal premotor cortex $(x=22, y=0, z=55)$ and the left insula $(x=-44, y=$ $-33, z=21$ ) (Fig. 6, top; Table 3). There were no regions where controls had larger post-training gray matter volumes than patients. For illustration purposes, we plotted the parameter estimates along with the $90 \%$ confidence interval at the peak location of each brain region against time (Fig. 6, bottom).

\section{Cerebellum-optimized VBM}

Training-related gray matter volume increase. A VBM analysis using a height threshold of $p<0.05$ corrected for multiple comparisons revealed no training-related cerebellar gray matter volume increase in either group. At $p<0.001$ (uncorrected; predetermined cluster size of 30.78 ), patients showed a post-training gray matter expansion in right Crus I ( $x=20, y=-71, z=-33$ ) (Fig. 7, top; Table 4), while in healthy controls, gray matter volume increase was found in right lobule VI $(x=34, y=-54, z=-31)$, extending into the adjacent region of Crus I, right lobule VIIIa extending into VIIIb $(x=30, y=-47, z=-47)$, and left Crus II $(x=-10, y=-78, z=-33)$ (Fig. 7, bottom; Table 4). No significant between-group gray matter differences were found within the cerebellum.

Differences in baseline gray matter volume; correlation in patients with ataxia scores. Patients revealed no cerebral regions with a reduced baseline gray matter volume when compared with controls neither at an FWE corrected $p$ level of 0.05 , nor at a trend level ( $p<0.001$, uncorrected). However, patients were found to have a reduced cerebellar gray matter volume at baseline compared with the control group (Fig. 8A). The medial and intermediate structures of the cerebellum were significantly different between the two groups ( $p<0.05$, FWE corrected).

There was a trend ( $p<0.001$, uncorrected; predetermined cluster size of 54.89) for the degree of ataxia in patients (SARA scores) to negatively correlate with the baseline gray matter volume of motor structures of the anterior cerebellum: lobules V (left: $x=-14, y=-46, z=-24)$, and VI bilaterally (left: $x=-28, y=-42, z=-23$, right: $x=21, y=-55, z=-18)$ (Fig. $8 B$ ). At the same $p<0.001$ (uncorrected; predetermined cluster size of 34.13 ), a positive correlation of ataxia scores (SARA) in patients with cerebral baseline gray matter volume revealed the following motor and non-motor structures: dorsal premotor cortex bilaterally (left: $x=-21, y=-1, z=52$, right: $x=27$, $y=6, z=55$ ), supplementary motor area bilaterally (left: $x=-5$, $y=8, z=66$, right: $x=8, y=-12, z=63)$, left precentral gyrus $(x=-23, y=-19, z=73)$, left caudate nucleus $(x=-15, y=8$, $z=22)$, left superior frontal gyrus $(x=-27, y=38, z=37)$, and right middle frontal gyrus $(x=41, y=21, z=40)$ (Fig. $8 C$ ).

\section{Discussion}

The objective of the present study was to evaluate whether a 2 week postural training improves balance performance in patients with cerebellar degeneration and identify macroscopic changes of those brain structures that facilitate this process. Results show that the patients' post-training improvements in balance performance were mainly associated with an increase in gray matter volume in the premotor cortex. This finding is based on a brain imaging analysis that corrected for multiple comparisons. How- 


\section{Training-related GM volume increase - PATIENTS}

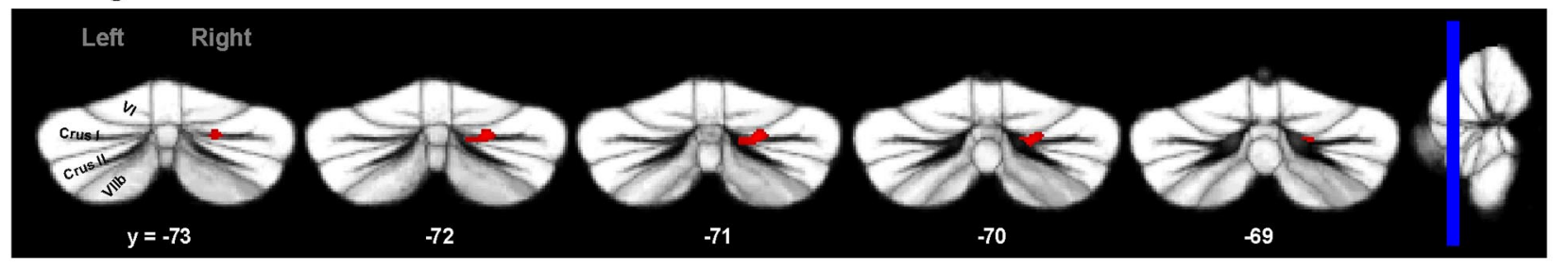

Training-related GM volume increase - CONTROLS

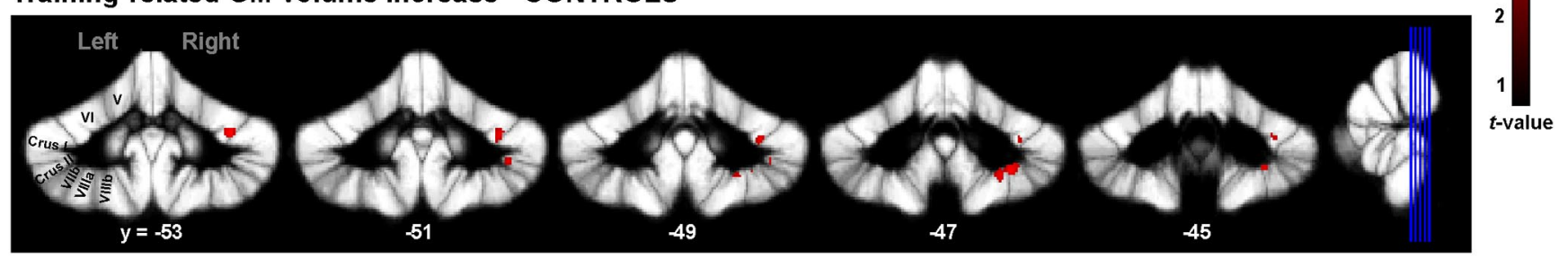

Figure 7. The cerebellum-optimized VBM analysis demonstrated training-related gray matter volume increase in patients in the right Crus I (top). In controls, gray matter volume increase in the right lobules VI/Crus I, VIIla/b is shown (bottom). Results are overlaid on the SUIT template and thresholded at $p<0.001$ (uncorrected; predetermined cluster size of 30.78 as partial correction). Color bar indicates $t$ values. $Y$ values indicate the coordinate in millimeters, in SUIT space. GM, gray matter.

Table 4. Summary of brain regions detected with cerebellum-optimized VBM analysis

\begin{tabular}{|c|c|c|c|c|c|c|c|}
\hline \multirow[b]{2}{*}{ Cerebellar region } & \multirow[b]{2}{*}{ Side } & \multicolumn{3}{|c|}{ Peak coordinate $(\mathrm{mm})$} & \multirow[b]{2}{*}{$k_{E}$} & \multirow[b]{2}{*}{$t$ value } & \multirow[b]{2}{*}{ Z-score } \\
\hline & & $x$ & $y$ & $z$ & & & \\
\hline \multirow{2}{*}{\multicolumn{8}{|c|}{$\begin{array}{c}\text { Training-related gray matter } \\
\text { volume increase }\end{array}$}} \\
\hline & & & & & & & \\
\hline \multicolumn{8}{|c|}{ Patients } \\
\hline Crus I & $\mathrm{R}$ & 20 & -71 & -33 & 131 & 4.03 & 3.82 \\
\hline \multicolumn{8}{|l|}{ Controls } \\
\hline VI & $\mathrm{R}$ & 34 & -54 & -31 & 414 & 4.49 & 4.20 \\
\hline VIIIla & $\mathrm{R}$ & 30 & -47 & -47 & 111 & 4.20 & 3.96 \\
\hline Crus II & $\mathrm{L}$ & -10 & -78 & -33 & 194 & 4.04 & 3.82 \\
\hline
\end{tabular}

Changes in gray matter volume are thresholded at $p<0.001$ (uncorrected; predetermined cluster size of 30.78 as partial correction). Anatomical locations of peak voxels are given in SUIT space. Cluster extent $\left(k_{E}\right)$, peak $t$ scores and Z-values are listed. L, left; $\mathrm{R}$, right.

ever, for the sake of completeness we also reported those brain areas that showed significant training-related changes based on the uncorrected imaging data albeit at a more conservative $\alpha$-level and using predetermined cluster size as partial correction. For an analysis that does not correct for multiple comparisons, there is an increased risk of type I errors, that is, false positives (Bennett et al., 2009). Thus, one needs to be cognizant that those data may merely indicate "trends" in the statistical sense. They are nevertheless informative as they outline more completely the possible network involved in the training-induced brain changes. They can serve as a guide for future follow-up studies examining a larger patient population using an ROI-driven approach to confirm the relationship between those brain areas that correspond to functionally relevant behavioral changes as the result of training.

Training-related postural changes

The current findings provide further evidence in support of the effectiveness of motor training in patients with cerebellar degeneration. Although cerebellar patients exhibited poorer performance than controls, they were able to improve postural stability to the same extent as healthy participants. The acquired balance improvements persisted over the 3 month period following training. Our results are in line with two previous studies reporting improvement and retention of motor function for up to one year following a 1 month intervention (Ilg et al., 2009, 2010; Miyai et al., 2012). However, while these studies used a conventional physiotherapeutic approach with a focus on measures of motor coordination, we here tested balance performance in a single, well defined postural task allowing us to associate gray matter changes to observable motor training effects.

Even though a constrained postural ability was trained, its positive effect on balance control transferred to another postural task. Learning to shift the COG on a dynamic platform to reach several target positions presented on a computer screen also led to a decrease of the sway length in a task where upright stance had been tested under different sensory conditions. Although several postural parameters correlated with the severity of the disease, no significant changes in ataxia scores over time were observed. Both Ilg et al. (2009) and Miyai et al. (2012) identified earlier a significant improvement in clinical ataxia scores, most likely because their coordinative training included tasks that more closely resemble items assessed in the ataxia scales ICARS and SARA (Trouillas et al., 1997; Schmitz-Hübsch et al., 2006).

\section{Training-related structural brain changes}

While gray matter volume increase was larger in cerebral areas in patients compared with controls, the opposite was found in the cerebellum, with a more pronounced increase in gray matter volume in controls compared with patients. This implies that motor improvements in patients with cerebellar degeneration appear to be driven by cerebral structures unaffected by the disease. In both cerebellar patients and controls, gray matter changes were found in supratentorial areas known to contribute to various aspects and stages of motor learning. In cerebellar patients, most changes were observed in the frontal cortex, whereas gray matter changes in occipitotemporal areas and basal ganglia prevailed in healthy controls.

We found no evidence to substantiate the claim that cerebellar patients increasingly recruit the basal ganglia circuits to compensate for their motor deficit (Wessel et al., 1995). In the patient group, the most compelling change in gray matter volume was seen in the dorsal premotor cortex (PMd). PMd projects to the primary motor cortex (M1) and cerebellum, and is involved in movement planning and early stages of motor learning (Picard and Strick, 2001; Müller et al., 2002; Vahdat et al., 2011). With 
respect to the cerebellum it is known that cerebellar motor areas (i.e., lobules VI and Crus I and VIII) are connected to primary motor and premotor cortices (Kelly and Strick, 2003; Hashimoto et al., 2010). Thus, training-related plastic changes in the cerebellar patients took part within components of the cerebellar-cortical loop not affected by the disease. Miyai et al. (2002) reported analogous findings in patients with hemiplegia due to stroke with the premotor cortex becoming involved in the restoration of gait.

When considering the results of the uncorrected brain imaging data, patients showed gray matter changes in addition to the premotor cortex, namely within the anterior cingulate gyrus and the insula. The anterior cingulate has known connections with the prefrontal cortex, and is involved in affect regulation and cognition. Since motor performance is impaired and movements become less automatized (Lang and Bastian, 2002), gray matter volume increase in the anterior cingulate gyrus may represent increased attention to the task performance and/ or increased use of cognitive strategies (Rossi et al., 2009; Zhu et al., 2012). The insula plays a major role in the vestibular cortical network, and gray matter expansion may be related to improved spatial orientation and self-motion perception (Ward et al., 2003, Lopez and Blanke, 2011).

Both patients and controls presented an increase in gray matter volume in temporal association areas. Participants had to displace their COG to reach various targets in space, and gray matter volume increase in temporal association areas may be related to processing of visuospatial inputs necessary for movement (Beauchamp et al., 2002, 2003; Saygin, 2007). In healthy controls, additional visual areas in the occipital lobe were associated with an improvement in balance control. Involvement of visual association areas are in line with findings of Draganski et al. (2004) in a visuomotor learning task. In controls, changes were also found within the hippocampus and the basal ganglia system. These structural changes may have been driven by the sequential requirements of the trained task (Ungerleider et al., 2002; Gheyen et al., 2010). Likewise, a recent study in healthy participants demonstrated the particular involvement of a component of the basal ganglia circuit (supplementary motor area) in learning to maintain postural stability during a complex wholebody dynamic balancing (Taubert et al., 2010). Moreover, the supplementary motor area was also found to be involved in balance control in stroke patients (Mihara et al., 2012).

With respect to gray matter changes in the cerebellum, these were more pronounced and extended in healthy controls than in patients. A cluster spanning lobule VI and Crus I was found to have an increase in gray matter volume in the control group. As outlined above, these areas have known connections with premotor and primary motor cortex. Gray matter volume increase in healthy participants most likely reflects improved adaptation of postural movements to the task requirements given the known contributions of the cerebellum to adaptive motor learning (Houk et al., 1996; Rabe et al., 2009). In addition, controls showed volumetric increase in lobule Crus II. Crus II has known connections to the prefrontal and parietal cortices (Dum and Strick, 2003; Prevosto et al., 2010; Buckner et al., 2011). Present gray matter changes in Crus II are probably related to the visuospatial aspects of the task. In patients increases were found in Crus I. This may indicate recruitment of cerebellar areas less affected by the disease, given that cerebellar degeneration was most marked in midline structures and least in the lateral hemispheres (Fig. 8A; Brandauer et al., 2008). On the other hand, these changes may also suggest repair of the affected cerebellar tissue. The two possibilities are not mutually exclusive given animal data showing that training can lead to neural repair in cerebellar degeneration. As outlined in the introduction, motor improvement has been shown to be accompanied by neuronal synaptogenesis and an increase in glial cell size in animal models of cerebellar degeneration (Klintsova et al., 2002). However, although both cellular mechanisms are thought to contribute to training-related gray matter increase in VBM (Zatorre et al., 2012), the functional relevance of observed VBM-related changes following training is not clear to date. 
Although the cerebellar vermis is concerned with whole-body posture and locomotion (Ouchi et al., 1999; Ioffe et al., 2007), no changes were detected in either controls or cerebellar patients. This was also the case for the primary motor cortex. Likewise, other VBM studies of motor training tasks report no changes in primary motor areas for reasons currently unknown (Draganski et al., 2004; Taubert et al., 2010).

In summary, structural changes related to sensorimotor training occurred in patients primarily within premotor cortex, a nonaffected neocortical region of the cerebellar-cortical loop. However, there was also weaker evidence that the 2 week training is associated with changes within the cerebellum itself. Whether these changes are simply the expression of residual cerebellar function reflecting the activity of structures that have always have been involved in sensorimotor learning, or whether sensorimotor training also induces reorganization and repair mechanisms within the cerebellum is still a matter of debate. In either case, findings reported herein represent promising news for patients with cerebellar degeneration.

\section{References}

Anheim M, Tranchant C, Koenig M (2012) The autosomal recessive cerebellar ataxias. N Engl J Med 366:636-646. CrossRef Medline

Ashburner J, Friston KJ (2005) Unified segmentation. Neuroimage 26:839851. CrossRef Medline

Beauchamp MS, Lee KE, Haxby JV, Martin A (2002) Parallel visual motion processing streams for manipulable objects and human movements. Neuron 34:149-159. CrossRef Medline

Beauchamp MS, Lee KE, Haxby JV, Martin A (2003) FMRI responses to video and point-light displays of moving humans and manipulable objects. J Cogn Neurosci 15:991-1001. CrossRef Medline

Bennett CM, Wolford GL, Miller MB (2009) The principled control of false positives in neuroimaging. Soc Cogn Affect Neurosci 4:417-422. CrossRef Medline

Berg KO, Wood-Dauphinee SL, Williams JI, Maki B (1992) Measuring balance in the elderly: validation of an instrument. Can J Public Health 83:S7-S11. Medline

Brandauer B, Hermsdörfer J, Beck A, Aurich V, Gizewski ER, Marquardt C, Timmann D (2008) Impairments of prehension kinematics and grasping forces in patients with cerebellar degeneration and the relationship to cerebellar atrophy. Clin Neurophysiol 119:2528-2537. CrossRef Medline

Buckner RL, Krienen FM, Castellanos A, Diaz JC, Yeo BT (2011) The organization of the human cerebellum estimated by intrinsic functional connectivity. J Neurophysiol 106:2322-2345. CrossRef Medline

Diedrichsen J (2006) A spatially unbiased atlas template of the human cerebellum. Neuroimage 33:127-138. CrossRef Medline

Diedrichsen J, Balsters JH, Flavell J, Cussans E, Ramnani N (2009) A probabilistic MR atlas of the human cerebellum. Neuroimage 46:39-46. CrossRef Medline

Draganski B, Gaser C, Busch V, Schuierer G, Bogdahn U, May A (2004) Neuroplasticity: changes in grey matter induced by training. Nature 427 : 311-312. CrossRef Medline

Driemeyer J, Boyke J, Gaser C, Büchel C, May A (2008) Changes in gray matter induced by learning-revisited. PLoS One 3:e2669. CrossRef Medline

Dum RP, Strick PL (2003) An unfolded map of the cerebellar dentate nucleus and its projections to the cerebral cortex. J Neurophysiol 89:634639. Medline

Durr A (2010) Autosomal dominant cerebellar ataxias: polyglutamine expansions and beyond. Lancet Neurol 9:885-894. CrossRef Medline

Friston KJ, Worsley KJ, Frackowiak RSJ, Mazziotta JC, Evans AC (1994) Assessing the significance of focal activations using their spatial extent. Hum Brain Mapp 1:214-220.

Gheysen F, Van Opstal F, Roggeman C, Van Waelvelde H, Fias W (2010) Hippocampal contribution to early and later stages of implicit motor sequence learning. Exp Brain Res 202:795-807. CrossRef Medline

Hashimoto M, Takahara D, Hirata Y, Inoue K, Miyachi S, Nambu A, Tanji J, Takada M, Hoshi E (2010) Motor and non-motor projections from the cerebellum to rostrocaudally distinct sectors of the dorsal premotor cortex in macaques. Eur J Neurosci 31:1402-1413. CrossRef Medline
Houk JC, Buckingham JT, Barto AG (1996) Models of the cerebellum and motor learning. Behav Brain Sci 19:368-383. CrossRef

Ilg W, Timmann D (2013) General management of cerebellar disorders: an overview. In: Handbook of the cerebellum and cerebellar disorders (Manto M, Gruol D, Schmahmann J, Koibuchi N, Rossi F, eds), pp 2349 2368. New York: Springer. CrossRef

Ilg W, Synofzik M, Brötz D, Burkard S, Giese MA, Schöls L (2009) Intensive coordinative training improves motor performance in degenerative cerebellar disease. Neurology 73:1823-1830. CrossRef Medline

Ilg W, Brötz D, Burkard S, Giese MA, Schöls L, Synofzik M (2010) Longterm effects of coordinative training in degenerative cerebellar disease. Mov Disord 25:2239-2246. CrossRef Medline

Ioffe ME, Chernikova LA, Ustinova KI (2007) Role of cerebellum in learning postural tasks. Cerebellum 6:87-94. CrossRef Medline

Ito M (1984) The cerebellum and neural control. New York: Raven.

Kelly RM, Strick PL (2003) Cerebellar loops with motor cortex and prefrontal cortex of a nonhuman primate. J Neurosci 23:8432-8444. Medline

Klintsova AY, Scamra C, Hoffman M, Napper RM, Goodlett CR, Greenough WT (2002) Therapeutic effects of complex motor training on motor performance deficits induced by neonatal binge-like alcohol exposure in rats: II. A quantitative stereological study of synaptic plasticity in female rat cerebellum. Brain Res 937:83-93. CrossRef Medline

Klockgether T, Paulson H (2011) Milestones in ataxia. Mov Disord 26: 1134-1141. CrossRef Medline

Lang CE, Bastian AJ (2002) Cerebellar damage impairs automaticity of a recently practiced movement. J Neurophysiol 87:1336-1347. Medline

Lopez C, Blanke O (2011) The thalamocortical vestibular system in animals and humans. Brain Res Rev 67:119-146. CrossRef Medline

Mihara M, Miyai I, Hattori N, Hatakenaka M, Yagura H, Kawano T, Kubota K (2012) Cortical control of postural balance in patients with hemiplegic stroke. Neuroreport 23:314-319. CrossRef Medline

Miyai I, Yagura H, Oda I, Konishi I, Eda H, Suzuki T, Kubota K (2002) Premotor cortex is involved in restoration of gait in stroke. Ann Neurol 52:188-194. CrossRef Medline

Miyai I, Ito M, Hattori N, Mihara M, Hatakenaka M, Yagura H, Sobue G, Nishizawa M (2012) Cerebellar ataxia rehabilitation trial in degenerative cerebellar diseases. Neurorehabil Neural Repair 26:515-522. CrossRef Medline

Müller RA, Kleinhans N, Pierce K, Kemmotsu N, Courchesne E (2002) Functional MRI of motor sequence acquisition: effects of learning stage and performance. Brain Res Cogn Brain Res 14:277-293. CrossRef Medline

NeuroCom International (2004) SMARTEquiTest System operator's manual. Clackamas, OR: NeuroCom International.

Ouchi Y, Okada H, Yoshikawa E, Nobezawa S, Futatsubashi M (1999) Brain activation during maintenance of standing posture in humans. Brain 122: 329-338. CrossRef Medline

Palmer SJ, Ng B, Abugharbieh R, Eigenraam L, McKeown MJ (2009) Motor reserve and novel area recruitment: amplitude and spatial characteristics of compensation in Parkinson's disease. Eur J Neurosci 29:2187-2196. CrossRef Medline

Picard N, Strick PL (2001) Imaging the premotor areas. Curr Opin Neurobiol 11:663-672. CrossRef Medline

Podsiadlo D, Richardson S (1991) The timed "Up and Go": a test of basic functional mobility for frail elderly persons. J Am Geriatr Soc 39:142-148. Medline

Prevosto V, Graf W, Ugolini G (2010) Cerebellar inputs to intraparietal cortex areas LIP and MIP: functional frameworks for adaptive control of eye movements, reaching, and arm/eye/head movement coordination. Cereb Cortex 20:214-228. CrossRef Medline

Rabe K, Livne O, Gizewski ER, Aurich V, Beck A, Timmann D, Donchin O (2009) Adaptation to visuomotor rotation and force field perturbation is correlated to different brain areas in patients with cerebellar degeneration. J Neurophysiol 101:1961-1971. CrossRef Medline

Rossi AF, Pessoa L, Desimone R, Ungerleider LG (2009) The prefrontal cortex and the executive control of attention. Exp Brain Res 192:489-497. CrossRef Medline

Saygin AP (2007) Superior temporal and premotor brain areas necessary for biological motion perception. Brain 130:2452-2461. CrossRef Medline

Schmitz-Hübsch T, Tezenas du Montcel S, Baliko L, Berciano J, Boesch S, Depondt C, Giunti P, Globas C, Infante J, Kang JS, Kremer B, Mariotti C, Melegh B, Pandolfo M, Rakowicz M, Ribai P, Rola R, Schöls L, Szymanski 
S, van de Warrenburg BP, et al. (2006) Scale for the assessment and rating of ataxia: development of a new clinical scale. Neurology 66:17171720. CrossRef Medline

Schmitz-Hübsch T, Giunti P, Stephenson DA, Globas C, Baliko L, Saccà F, Mariotti C, Rakowicz M, Szymanski S, Infante J, van de Warrenburg BP, Timmann D, Fancellu R, Rola R, Depondt C, Schöls L, Zdzienicka E, Kang JS, Döhlinger S, Kremer B, et al. (2008) SCA Functional Index: a useful compound performance measure for spinocerebellar ataxia. Neurology 71:486-492. CrossRef Medline

Strupp M, Kalla R, Claassen J, Adrion C, Mansmann U, Klopstock T, Freilinger T, Neugebauer H, Spiegel R, Dichgans M, Lehmann-Horn F, Jurkat-Rott K, Brandt T, Jen JC, Jahn K (2011) A randomized trial of 4-aminopyridine in EA2 and related familial episodic ataxias. Neurology 77:269-275. CrossRef Medline

Taubert M, Draganski B, Anwander A, Müller K, Horstmann A, Villringer A, Ragert P (2010) Dynamic properties of human brain structure: learning-related changes in cortical areas and associated fiber connections. J Neurosci 30:11670-11677. CrossRef Medline

Thach WT, Goodkin HP, Keating JG (1992) The cerebellum and the adaptive coordination of movements. Annu Rev Neurosci 15:403-442. CrossRef Medline

Timmann D, Konczak J, Ilg W, Donchin O, Hermsdörfer J, Gizewski ER, Schoch B (2009) Current advances in lesion-symptom mapping of the human cerebellum. Neuroscience 162:836-851. CrossRef Medline

Trouillas P, Takayanagi T, Hallett M, Currier RD, Subramony SH, Wessel K, Bryer A, Diener HC, Massaquoi S, Gomez CM, Coutinho P, Ben Hamida M, Campanella G, Filla A, Schut L, Timann D, Honnorat J, Nighoghossian N, Manyam B (1997) International Cooperative Ataxia Rating Scale for pharmacological assessment of the cerebellar syndrome. J Neurol Sci 145:205-211. CrossRef Medline

Tzourio-Mazoyer N, Landeau B, Papathanassiou D, Crivello F, Etard O, Delcroix N, Mazoyer B, Joliot M (2002) Automated anatomical labeling of activations in SPM using a macroscopic anatomical parcellation of the MNI MRI single-subject brain. Neuroimage 15:273-289. CrossRef Medline

Ungerleider LG, Doyon J, Karni A (2002) Imaging brain plasticity during motor skill learning. Neurobiol Learn Mem 78:553-564. CrossRef Medline

Vahdat S, Darainy M, Milner TE, Ostry DJ (2011) Functionally specific changes in resting-state sensorimotor networks after motor learning. J Neurosci 31:16907-16915. CrossRef Medline

van Eimeren T, Siebner HR (2006) An update on functional neuroimaging of parkinsonism and dystonia. Curr Opin Neurol 19:412-419. CrossRef Medline

Ward NS, Brown MM, Thompson AJ, Frackowiak RS (2003) Neural correlates of motor recovery after stroke: a longitudinal fMRI study. Brain 126:2476-2496. CrossRef Medline

Wessel K, Zeffiro T, Lou JS, Toro C, Hallett M (1995) Regional cerebral blood flow during a self-paced sequential finger opposition task in patients with cerebellar degeneration. Brain 118:379-393. CrossRef Medline

Worsley KJ, Marrett S, Neelin P, Vandal AC, Friston KJ, Evans AC (1996) A unified statistical approach for determining significant signals in images of cerebral activation. Hum Brain Mapp 4:58-73. CrossRef Medline

Yardley L, Beyer N, Hauer K, Kempen G, Piot-Ziegler C, Todd C (2005) Development and initial validation of the Falls Efficacy ScaleInternational (FES-I). Age Ageing 34:614-619. CrossRef Medline

Zatorre RJ, Fields RD, Johansen-Berg H (2012) Plasticity in gray and white: neuroimaging changes in brain structure during learning. Nat Neurosci 15:528-536. CrossRef Medline

Zhu L, Mathewson KE, Hsu M (2012) Dissociable neural representations of reinforcement and belief prediction errors underlie strategic learning. Proc Natl Acad Sci U S A 109:1419-1424. CrossRef Medline 